\title{
PSYCHOLOGICAL ASPECTS OF SPACE FLIGHTS
}

\author{
Brig. Gen. Pil. Cosm. Mirosław HERMASZEWSKI
}

Mankind has always been fascinated by the unknown. Many had dreamt to look at the Earth from the bird's perspective. The first ones to achieve this were Jean-François Pilâtre de Rozier and marquis François Laurent d'Arlandes who took off the Earth in a hot air balloon constructed by Montgolfier brothers in 1793. In 1903, Wright brothers presented the mankind with the gift of the airplane, thus opening up the aviation era. The dreams to fly in the clouds have come true, and aviation soon became one of the aspects of our lives.

However, human imagination and dreams had always reached far beyond the Earth itself. The space above us intrigued many thinkers with its unimaginable vastness and mysteriousness. It stimulated us to track the heavenly bodies, stirred up our imagination and raised hopes that "perhaps one of these days...". The day has come on April $12,1961,168$ years after the first manned balloon flight and 58 years after the Wright brothers' plane flight. Yuri Gagarin took off the earth to go beyond the borders of Earth's atmosphere and gravity.

These two events of the previous century were of epoch-making importance for the progress of humanity. Although both were a response to the same call to pursue one's dreams and expand one's knowledge, both inventions were developed in completely different conditions. For the Wright brothers, the dream-come-true stage was the construction of the plane. Driven by their enthusiasm, they were ready to face unknown adversities they could not even imagine, and thus foresee, define and evaluate. The little experience in balloon flights could not provide knowledge on the dynamics of the flight, and the medical knowledge now referred to as aviation medicine was unavailable. At that time, the one who built the airplane was himself a bird's kin. Unfortunately, a tragedy followed in the footsteps of the initial successes of free flights. Thomas Selfridge died in a crash after a propeller blade snapped off the plane.

Gagarin's flight was a natural consequence of our pursue of knowledge; it became possible owing to the experience gained by aviators. Before Gagarin entered the rocket that had been constructed for many years by thousands of specialists, he had to undergo a long preparation procedure, acquire new theoretical knowledge, grasp the skills of operating complex machinery and, most of all, prepare himself, his body and his mind for the encounter with the unknown.

Although the already-rich resources of aviation medicine were available for the fledgling cosmonautics, not all experiences could be adapted to space flights. The space stirred up the imagination of scientists who were well aware of numerous gaps in their knowledge. One thing was certain, however: that the man entering the space was to encounter an unusual world and that the enterprise would be complex in many aspects; in particular, it would be very, very dangerous and involve a number of unknown mental experiences.

Figure: 1 • References: 7 • Full-text PDF: http://www.pjamp.com • Copyright @ 2013 Polish Aviation Medicine Society, ul. Krasińskiego 54/56, 01-755 Warsaw, license WIML • Indexation: Index Copernicus, Polish Ministry of Science and Higher Education 
Before Gagarin's takeoff, scientists attempted to define the cosmonauts' environment and work conditions as well as to identify factors that might impact their lives, safety and activities. Today, it is known beyond any doubt that humans may stay and work in outer space for several months, perform external assembly tasks and function on the surface of the Moon. The working environment of a cosmonaut is much different from the working environment of a pilot, although there are also some similarities. This seems to evolve with time. Increasing velocities and heights were reached. The zero gravity phenomenon was discovered. The efficiency and reliability of human actions depend on numerous diverse and complex factors; they also come at the price of psychophysical exertion unknown in other professions.

Living and working conditions of a cosmonaut are affected by factors of varying incidence and activity, and the impact of these factors depends on individual predispositions of a cosmonaut, his or her theoretical knowledge, practical skills (developed in simulators or during previous space missions), the stage of the space flight and, which is perceived very clearly, on the nature and complexity of the mission.

1. External factors - hostile, life-threatening environment:

- absolute vacuum

- very high altitude (hundreds of kilometers)

- very high speed (ca. $8 \mathrm{~km} / \mathrm{s}$ )

- temperature variability/extreme temperature ranges

- risk of collisions with micrometeorites, space matter residues and man-made objects

- cosmic radiation

2. Internal factors - psychophysiological factors associated with the conditions of living in a spaceship:

- zero gravity (particularly difficult in the period of adaptation), dehydration, disturbed cardiovascular function, disturbed cerebellar function leading to misinterpretations of one's position in space, discomfort and reduced ability to work

- limited living space

- limited motor activity (hypokinesia)

- specific nutrition (lack of fresh and natural products, water recovered from the products of body metabolism)

- lack of normal diurnal rhythm (day/night changes 16 times per 24 hours)

- specific microclimate (regeneration of closed-system air)

- necessity to work in the same team
- limited ability to rest and relax

- lack of privacy

- feeling overworked

- requirement to stay continuously alert

3. Physical factors resulting from flight dynamics:

- vibrations

- strong vibrations and noise

- increasing linear accelerations (up to $6.5 \mathrm{~g}$ upon launch, $4.5 \mathrm{~g}$ to $10-12 \mathrm{~g}$ upon landing) and rapid drops of acceleration upon switching off the engines of the successive levels of the launch vehicle

- rapid and frequent changes of external lighting (16 times per 24 hours)

- changes in flight parameters upon approaching and docking maneuvers

- unusual, foreign sounds

- return to gravity (reducing speed in the atmosphere, strong vibrations, strongly perceived gravity load, visible plasma flames)

- inability to intervene in the process of leaving the orbit

- brutal shake upon parachute opening and limited control of the process

- inability to watch the process of approaching the Earth (molten,

- opaque porthole glass)

- sudden and "soft" landing.

The aforementioned factors affecting the spaceship crew at different times and with different intensities lead to emotional strain and thus to development of stressful situations regardless of previous training.

Stress may be defined in various ways. I decided to assume the definition stating that stress is a group of factors posing a certain risk. The psychophysical reaction to stress depends on individual's predisposition (resistance), ability to perceive and assess the situation as well as on the degree of specialist preparation for acting in the specific conditions of a space flight.

It follows that stress is a result of the awareness of risks at every stage of the space flight, and even prior to the flight, as well as of the sense of responsibility resulting from the obligation to perform the entrusted tasks.

Stress leads to biological and psychophysiological reactions in the body.

Biological reactions are manifested as increased bodily activation, leading to physiological changes within the cardiovascular, respiratory, and alimentary systems, biochemical reactions, EEG records, electrolyte profiles etc., allowing to employ physiological and neurophysiological research techniques). 


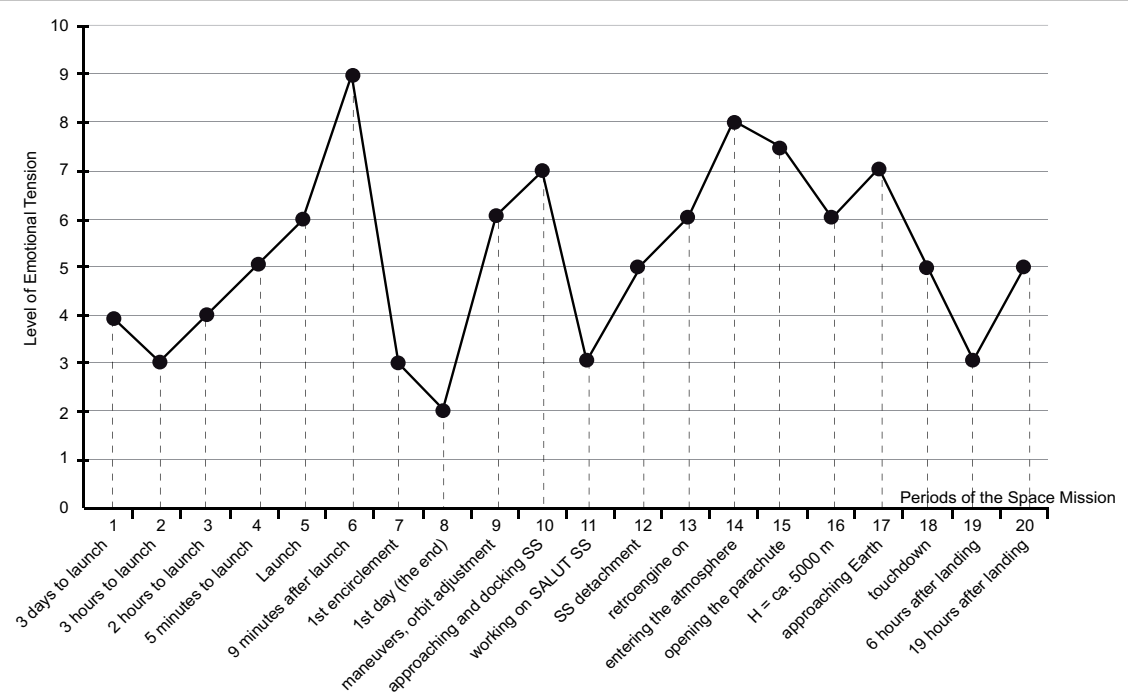

\begin{tabular}{|c|c|c|}
\hline Lp. & Time & My hand notes \\
\hline 1. & 3 days to launch & "It's so close, hope nothing bad happens or they would cancel the launch" \\
\hline 2. & 3 hours to launch & "This is it - a bath, a meal (my favorite chicken soup), spacesuit on" \\
\hline 3. & 2 hours to launch & "Spaceship cabin, systems checkup" \\
\hline 4. & 5 minutes to launch & "Work completed, waiting, time drags by" \\
\hline 5. & Launch & "So it started, we're going up, much work, little time" \\
\hline 6. & 9 minutes after launch & "Jettisoning, the orbit, zero gravity, I'm hanging, I don't believe it's real" \\
\hline 7. & 1st encirclement & "Colorful, beautiful, fantastic, am I hanging upside down?" \\
\hline 8. & 1st day (the end) & "Work has knocked me out, let's get some sleep" \\
\hline 9. & maneuvers, orbit adjustment & "No time to look at E" \\
\hline 10. & approaching and docking SS & "It's hard, but we must make it" \\
\hline 11. & working on SALUT SS & "It's cool, but something haunts sometimes" \\
\hline 12. & SS detachment & "Pity we're coming back" \\
\hline 13. & retroengine on & "Pray it doesn't starve" \\
\hline 14. & entering the atmosphere & "Look at all this burning, beautiful and horrible, awful vibrations" \\
\hline 15. & opening the parachute & "Pray the rag works $(9.6 \mathrm{~km}) "$ \\
\hline 16. & $\mathrm{H}=$ ca. $5000 \mathrm{~m}$ & "A solid shock - gravity load 6.5 g, it's not E yet" \\
\hline 17. & approaching Earth & "Can't see anything, is it going to be soft?" \\
\hline 18. & touchdown & "Soft, sure! - hit, dragging, jolts, no doubt it's the Earth" \\
\hline 19. & 6 hours after landing & "Relax - pool, sauna, no journalists, champagne, no gabbing" \\
\hline 20. & 19 hours after landing & "The Kremlin, decoration, I am dead tired but have to talk" \\
\hline
\end{tabular}

SS - Space Station

E- Earth

Fig. 1. Changes in Emotional Tension during the Space Mission Soyuz 30 - Salyut 6 in 1978. Subjective feelings by General Mirosław Hermaszewski.

Psychophysiological reactions lead to increased emotional strain and the onset of defense reactions (one may experience accumulated negative physiological reactions, such as rapid increase in heart rate and blood pressure, increased perspiration, respiratory rate etc.)

The emotional strain can be divided into three stages:

\section{1. mobilization:}

- "it has to be done"; "I want it to be done"; "I was recruited to do it"
2. increasing feeling of being upset (as emotional strain is intensified)

- psychomotor and cognitive functions are impaired

3. behavioral disorganization (upon high and rapid increase in emotional strain)

- perceptive, cognitive and motor functions become disorganized, ability to logically think and act is impaired, individual focuses on a certain, sometimes insignificant element, forgets the well-trained tasks, experiences psychological blockade. 
Intensification of emotional changes as a result of stress may affect only some or most bodily functions. Changes may develop gradually or rapidly in relation to the impending risks.

Defense reaction (another form of psychophysiological reaction to stress):

- elimination of the course of the stress or employment of another mode of behavior.

Stress resulting from the awareness of potential threat to one's life accompanies every crew at every stage of their space mission. It may be associated with the risks to crew's lives due to a failure (explosion) of the rocket on the launch pad, when the crew members have no chance of saving themselves. Serious threats may arise as the rocket is brought to the orbit if the engines of the successive levels of the launch vehicle fail to operate. The space station approach and docking stage is also dangerous as it is associated with the possibility of colliding with the object to be docked. When on the orbit, there is risk of failures in operation of the orientation and steering equipment or of the drive system as well as risk of collisions with micrometeorites. When leaving the orbit, there are doubts with regard to proper operation of the automated steering system and to proper resistance of the landing capsule to high temperatures. Emotional strain is further increased by awaiting for the main parachute to open and is experienced until touchdown.

Another reason for stress is the awareness of one's responsibility and the risk of mission failure due to technical reasons, mainly to possible errors (committed by self).
The enclosed figure presents my subjective assessment of the intensity of emotional strain during a space flight (Fig. 1).

Let me highlight that in my case the sense of danger underwent essential reevaluations. Before the launch and during the flight to the orbit I considered potential failures only from the technical standpoint of the operator. Personal danger was somewhat in the background, as the primary goal was to enter the orbit.

On the day of coming back, my system of values was completely reversed. When we took our seats in the spaceship and prepared for the detachment from the space station, I became anxious of whether we would surely come back to Earth: whether the technology would work, whether we as the crew would stand up to the task. At that time, to my surprise, I recalled scenes from my childhood when despite having been warned I used to climb even the tallest trees. I felt happy, but one glance down at the ground was enough to fill me with fear. Why did I climb up here? Can I make it safely down there?

My thoughts started revolving around tragic fates of my predecessors and the memories of days spent on the orbit became completely unimportant. I just wanted to put my feet on the ground as soon as possible. I stopped these considerations to take up mu duties as an operator. After my flight, I returned to them many times, detail after detail, particularly after the disasters of Challenger and Columbia space shuttles as well as after emergency escape of the Soyuz T-10-1 crew three seconds before the rocket exploded.

\section{AUTHORS' DECLARATION:}

Study Design: Mirosław Hermaszewski; Data Collection: Mirosław Hermaszewski; Manuscript Preparation: Mirosław Hermaszewski; Funds Collection: Mirosław Hermaszewski. The Author declares that there is no conflict of interest.

\section{BIBLIOGRAPHY}

1. Barański, S., ed. (1977) Medycyna Lotnicza i Kosmiczna. Warsaw: PWNL.

2. Glushko, V. P., ed. (1985) Kosmonavtika: Entsiklopediia (Space Encyclopedia). Moscow: Izdatel'stvo sovietskaia entsiklopediia.

3. Kosmicheskaya Biologiya i Aviakosmicheskaya Meditsina (2001).

4. Kwarecki, K., Terelak, J. (1980) Medycyna i Psychologia Kosmiczna. Warsaw: Wiedza Powszechna.

5. Medycyna Lotnicza (1978). 59.

6. Postępy Astronautyki (1979). 12.

7. Włoszczyński, R., ed. (1976) Psychologia Lotnicza. Warsaw: MON

Cite this article as: Hermaszewski M: Psychological Aspects of Space Flights. Pol J Aviat Med Psychol, 2013; 19(3): 5-8. 